\title{
Impact of PLP on Student Learning: Initial Results
}

\author{
Dr. Rebecca L. Damron, Oklahoma State University \\ Dr. Sohum A Sohoni, Arizona State University, Polytechnic campus
}

Dr. Sohoni is an assistant professor in the Department of Engineering at Arizona State University's College of Technology and Innovation. He received his Ph.D. in Computer Engineering from the University of Cincinnati in 2004 and his bachelor's degree in Electrical Engineering from COEP at Pune University in 1998. After his Ph.D., he worked as an assistant professor at Oklahoma State University from 2005 to 2012. Dr. Sohoni's research interests are broadly in the area of computer architecture and performance analysis. He has recently expanded his research interests to include engineering education, and has published his work at ASEE's national conference and ASEE's Midwest section conference. He advises several undergraduate, M.S., and Ph.D. students. Dr. Sohoni believes that classroom instruction needs to incorporate the presentation techniques of today, as well as interactive teaching methodologies such as case studies and team learning. He is a popular and well-respected instructor, and has received several teaching awards including the CEAT Halliburton Excellent Young Teacher Award in 2009 and the Regents Distinguished Teaching Award in 2010 at Oklahoma State University.

\section{Dr. YoonJung Cho, Oklahoma State University}

Dr. YoonJung Cho is an assistant professor in the School of Applied Health and Educational Psychology at Oklahoma State University. Her research is focused on students' achievement motivation and selfregulated learning process and teachers' motivation and its impact on instructional practices, both in traditional classroom setting and online instruction. She is also interested in developing cognitive and psychological scales measuring learning, motivation, and emotion.

\section{Dr. Kerri S Kearney, Oklahoma State University}

Dr. Kerri Kearney is an associate professor of educational leadership at Oklahoma State University. Her professional experience is in both education and consulting (organizational development, and executive coaching). She holds an M.B.A. and an Ed.D. Her research agenda primarily focuses on the emotional impacts of human transition, human learning, other mothering, and visual methodologies in qualitative research. 


\title{
Impact of PLP on Student Learning: Initial Results
}

\begin{abstract}
The Progressive Learning Platform (PLP) is a System on a Chip design with accompanying tools reflecting a contemporary CPU architecture. This pilot study examines the impact of PLP on student learning in an introductory microprocessors class. To examine the impact on learning, students were required to write reflections about their learning every week after their lab experience. Reflections were then analyzed from a corpus-based discourse analytic perspective for what kind of knowledge the students gained in the PLP experience, procedural or declarative. Additionally, the language in the reflections was analyzed for stance- the students' perspectives on what they claimed they had learned. Results showed that students were gaining procedural knowledge throughout the semester. In this PLP experience, which follows a trajectory of research, implementation and integration, the procedural knowledge was articulated with less evaluation than later when students showed more stance, i.e. expression of attitude toward the knowledge, and integration of their learning.
\end{abstract}

\section{Introduction}

This paper provides initial results on the impact of using the Progressive Learning Platform (PLP) ${ }^{1-3}$ in a microprocessors course. The PLP is a platform that facilitates experiential learning for students taking courses in digital design, microprocessors, and computer architecture. The long-term vision for the PLP is to provide an alternative and experiential way of teaching computer engineering by establishing the computer engineering curriculum around a carefully designed learning platform. PLP provides a common development platform using a Field Programmable Gate Array (FPGA) board and is comprised of a set of digital tools including a software development environment (IDE), an instruction set architecture (ISA), a reference design in Verilog reflecting a contemporary CPU architecture, and Verilog modules for inputoutput interfacing. In addition to the software and hardware, PLP provides curricular materials like tutorials, projects, and quizzes. All parts of the system are open-source and publicly hosted; a public mailing list serves as a communication channel between users and developers of the system. PLP's strengths are its vertical integration and ability to connect fundamentals like programming and compiling with the underlying hardware.

With an overarching system like PLP, different aspects are taught and used in different courses, and students experience how concepts in different computer engineering courses are related to each other. Other highlights of the PLP system are a 'hands-on' experience with real hardware early in the computer engineering curriculum, a focus on class-wide collaboration, and an emphasis on communication.

Typical PLP-based courses have a large active learning component, with instructors working on PLPTool in the classroom and students working on large projects. PLPTool is a programming environment/tool in which you can write assembly code, run it, test it, and visualize it as it runs on the simulated hardware. Course grades are determined through documentation of the project work in various forms including wikis, formal presentations, and informational team-to-team 
presentations. The purpose of this study was to examine student perceptions of the types of knowledge acquired, as revealed by analysis of their language in written reflections, while participating in a microprocessors course that incorporated PLP in.

\section{Informing Theories}

This study draws on the theories of reflection for professional development, corpus linguistics and stance, and declarative and procedural knowledge.

\subsection{Reflections}

To achieve true technical expertise, Schön ${ }^{4}$ calls for a move away from technical rationality (knowing the technical facts) to reflection-in-action (engaging and understanding the process of applying the facts) for professionals. Reflection-in-action calls for a different kind of knowing: in order to gain technical expertise, professionals must be able to name and frame problems, that is, 'problem set' before they can problem solve (p. 40). This is especially so for engineers. As they go about their everyday practice they obtain a knowing that is in the action itself (p. 49). Schön focuses on the design professions as a place where the designer "works in particular situations, uses particular materials, and employs a distinctive medium and language" (p. 79). This is a complex process and requires a 'conversation' with the process, one that is reflective, "the designer reflects-in-action on the construction of the problem, the strategies of action, or the model of the phenomena, which have been implicit in his moves" (p. 79). Stevens and Cooper ${ }^{5}$ have shown the benefits of journal keeping, or reflective writing, for learning and draw on Schön's work to demonstrate that reflective writing assists professionals and novices to become more effective. Bolton ${ }^{6}$ argues that reflection helps us learn and examine events, and effective reflection is a means of giving individuals authority over their learning. This type of informal writing has been incorporated into the engineering classroom with success ${ }^{78}$. 'Incidental' or reflective writing was shown to improve problemsolving abilities as well as abilities to monitor thinking and learning strategies ${ }^{9}$. In this study, students in a lab section of a computer engineering course that uses PLP produced written reflections based on elicitor questions that deliberately focused on applicable course concepts, functions, materials and teamwork. This deliberately constructed reflection-in-action process was then analyzed for students' perceptions of their learning.

\subsection{Corpus Informed Discourse Analysis}

Corpus linguistics covers a range of approaches, both quantitative and qualitative, but at essence is an examination of large sets of texts (that have been produced in the real world) for patterns of language use ${ }^{1011}$

111213 . The advent of more sophisticated technologies has allowed linguists to examine large quantities of text. Traditionally, examination of lexical items, or words, was the focus of corpus linguistics; however, recently more work with larger chunks, phrases or multi-word clusters has yielded new theoretical insights into the nature of naturally occurring language. For the purpose

of this study, analysis of multi-word groups that appeared in students' written reflections provided important insights into each student's 'stance,' or personal engagement and positioning 
toward learning as revealed through language.

\subsection{Evaluation (Stance)}

Evaluation ${ }^{10} 14 \quad 15$ and stance ${ }^{13} 16 \quad 17$ ways of examining the subjectivity of the writer. A consideration of metadiscourse ${ }^{18} 19$ "embodies the idea that communication is more than just the exchange of information, goods or services; communication also involves personalities, attitudes and assumptions of those who are communicating ${ }^{18}$ (p. 3). DuBois ${ }^{20}$ articulates a stance triangle in which the stance taker 1) evaluates an object 2) positions a subject (usually the self) and 3) aligns with other subjects. There are various grammatical devices that express stance ${ }^{17}$, one of which is complement clauses controlled by a verb for example, I hope that I've plugged it in properly. (p. 969). Hope, in this case shows the speaker's attitude of hope toward the clause or proposition 'I've plugged it in properly'. As we look at the reflections in the data set, the stancetaker is the student and the object of evaluation is a complement clause that is part of a verb+complement. Semantically, there are several types of stance: attitudinal (personal attitudes and feelings), style of speaking (writer comments on the communication) and epistemic (writer comments on the status of information such as certainty or doubt, actuality, precision, source of knowledge, or perspective) ${ }^{17}$. In 2011, Hunston ${ }^{10}$ did a qualitative analysis of evaluation in texts demonstrating that 'phraseology' or multi-word clusters express evaluation (or stance). For this study, we draw on her work to examine the epistemic stance of the students' reflections on their learning. To prevent confusion of terms, we used only the term 'evaluation'.

\subsection{Declarative Knowledge versus Procedural Knowledge}

Numerous research studies have shown that knowledge plays an important role in memory and learning (e.g., critical thinking and problem solving) ${ }^{21}$. The role of knowledge in learning varies depending on the types of knowledge ${ }^{22}$. Researchers have identified distinctive differences between declarative and procedural knowledge. Declarative knowledge refers to knowing about something (i.e., 'what' things are), such as concepts, facts and principles that we know; procedural knowledge refers to knowing 'how' to perform something ${ }^{23}$. For instance, declarative knowledge includes knowing names of animals, numbers and colors. Procedural knowledge includes knowing how to drive a car and how to ride a bicycle. Procedural knowledge contains both informational and behavioral aspects of knowledge. This leads to different views about the relationship between declarative and procedural knowledge. Some researchers claim that they are two separate entities (i.e., informational and behavioral knowledge) while others argue that they are connected and acquired simultaneously. Anderson ${ }^{24}$ stated that the acquisition of declarative knowledge occurs prior to procedural knowledge acquisition and the former evolves gradually and is translated into procedural knowledge with practice. On the other hand, Willingham and Goedert-Exchmann ${ }^{25}$ argued that learners tend to simultaneously acquire both informational and behavioral components in the process of learning a new procedure. A question of interest for this study was what kind of learning and knowledge the students gained in the context of the PLP course as expressed in their reflections.

3. Program/Site and Participants 
The course was an undergraduate microprocessors course at a large public university in the United States. The student body comprised of an almost even split between sophomores and juniors. Because courses in a PLP-incorporated curriculum promote cooperative learning, communications skills, and other soft engineering skills, in addition to technical skills, students were initially grouped into self-selected pairs. For the first 4 lab assignments (approximately 6 weeks), students worked in these pairs without much collaboration across different pairs. For the final project, which began by week 7 and continued through week 15, teams of 4-5 students came together to work on a class-wide design project (see Figure 1). Emphasis was placed on inter- and intra- team collaboration. Formal communication and documentation took place on the student- driven course Wiki. Communication was facilitated by a student project manager elected by the students. The project manager had final administrative rights over all design and implementation decisions. Moving the control of these components from the instructor to the project manager enabled the instructor to further assume the role of facilitator; this shift in leadership/authority encouraged both real and perceived authenticity of learning (that which mimics the real world) for students.

Each student team consisted of the team roles of team leader, documentation expert, and lead engineer. The team leaders from each team met regularly to ensure that proper communication of design efforts was made. Again, this provided a unique opportunity to extend student learning to include the interpersonal communication challenges of teaming, a critical real-world set of skills too often not addressed in engineering education. The course emphasized the course project and did not include mid-term or final examinations. Weekly quizzes monitored ongoing learning but had little impact on course grades. Additionally, there were many inclass assignments, and teams provided weekly in-class oral status reports.

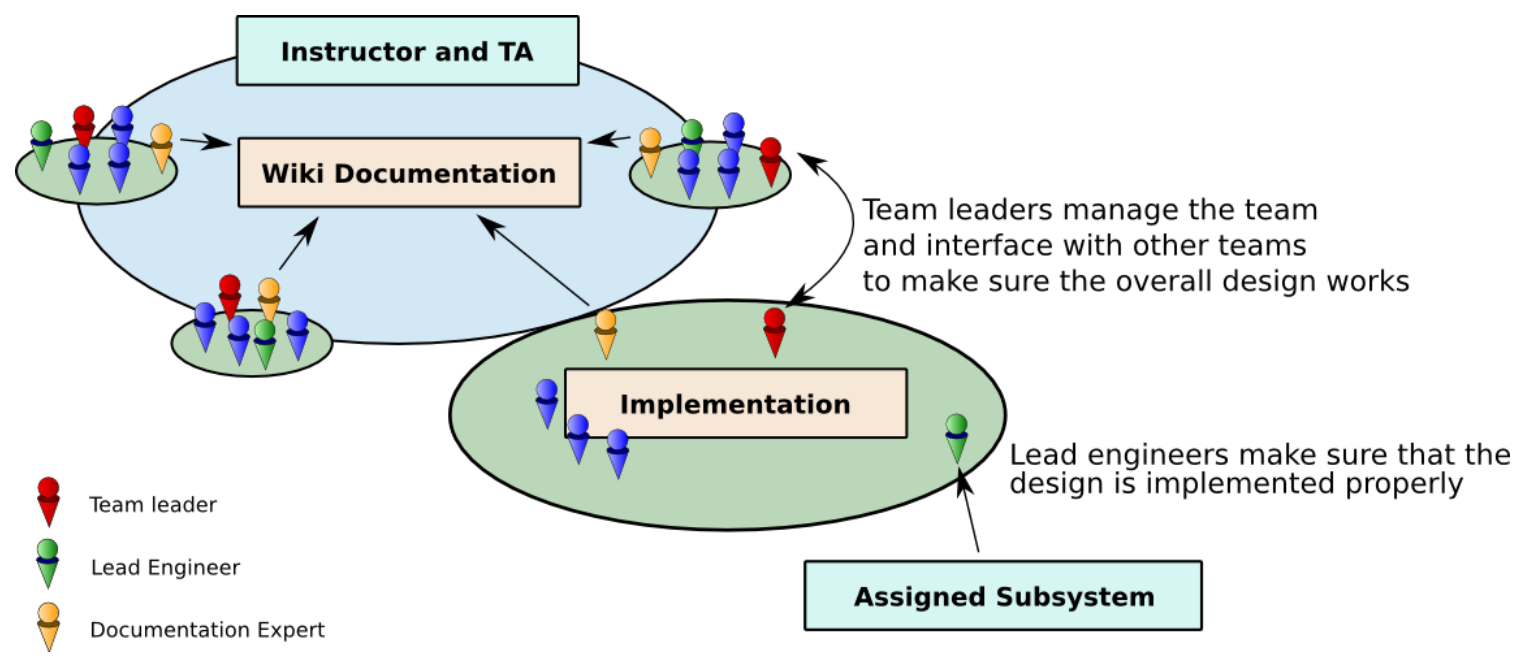

Figure 1: Teams. Figure shows how teams were formed and the roles of team members in the collaborative project ${ }^{26}$.

The project, which lasted for most of the semester, was split into three phases: research, implementation, and integration. Teams worked collaborative (across multiple teams) to complete a remote controlled robot project outfitted with the PLP system. The goal of the project was to program the robot to navigate an obstacle course both manually and autonomously. 
The research phase lasted for approximately one month and teams learned in great detail the aspects of their part of the overall design. It was during this phase that general instruction over microprocessors and assembly language was provided in a lecture format. Teams were asked to learn about material relevant to their part of the design, create block diagrams, fully define signals that impact other teams, and document all of their work on the course Wiki. At the end of the research phase, teams delivered formal presentations of their findings. Other students, as well as an assessment board made up of the instructor, other knowledgeable instructors, and key graduate students, were also present for the presentation. The assessment board was responsible for assessing the team on the effectiveness and clarity of communication of their part of the design, as well as their understanding of the overall design. Other students were encouraged to ask questions as well, particularly about how that team's design impacted their own work. The grade for the research phase was based on the combined perspectives of the assessment board.

The implementation phase was the longest phase of the design; within this phase, students used the PLP system to implement their designs from the research phase. Communication remained critical in this phase, as changes could have significant impact on the work of other teams. All teams provided up-to-the-minute documentation on the course Wiki, which enabled the teams to use and build upon others' work. All implementations were required to meet project specifications in order to move to the integration phase.

The integration phase was the final phase of the project. In this phase, students completed necessary integration of their overall designs, created a project video, finalized all documentation, and created a demonstration for an end-of-semester College of Engineering Design Day, where students demonstrate their semester projects in the hallways of the Engineering College.

\section{Methods}

A corpus-based discourse analytic approach (see previous section on Informing Theories) was taken to examine the students' reflections for types of knowledge acquired. This process facilitated an identification of the epistemic stance as expressed in verb+complement clause clusters.

\subsection{Written Reflections}

Student reflection prompts were developed based on the lab objectives and focused on students' perceptions of their learning in each of the phases for the course. Labs 1-4 were completed in pairs of students and Lab 5, which had several parts, was completed in teams. Students responded to the reflections individually and posted their work to the online learning system Desire to Learn. Reflections were written by 39 individual students.

Students were asked to respond to a series of specific questions (prompts) following the completion of each Lab. Questions for Labs 1 - 4 were:

Lab 1: Based off the first lab, what did you learn? What do you think you will need to 
learn for this class?

Lab 2: After writing your algorithm and discussing your work with the TA, respond to the following question: How did your discussion with the TA help you write and/or revise your algorithm? After writing your program and discussing your work with the TA, respond to the following question: How did your discussion with the TA help you write and/or revise your program? Based on the two earlier tasks and discussions, how did you and your partner write the algorithm and program? How did the discussion and partnership help you complete the final Lab 2 Task?

Lab 3: Explain what you've learnt so far to a person who isn't familiar with the subject matter.

Lab 4: This lab requires you to consider a user. How did this user affect how you did the task? What is an interrupt? How did you go about learning how to integrate the interrupts?

The series of reflective questions for the course project focused on the learning done in teams and the team process:

Lab 5 Reflection 1: How has your group worked together toward developing a complete understanding of your subsystem? How did individual team members contribute to this understanding?

Lab 5 Reflection 2: Did your group have any "false starts" or begin down a path only to have to turn back when conducting research for your program? Describe in detail what happened. For example, what specific decision led you to the "false start"? If not, why do you think your team was able to progress so smoothly?

Give a specific example.

Lab 5 Reflection 3: In the process of learning about your subsystem and planning your program, what problems did your team have to resolve? Describe the problems and why you think they occurred. What about working as a team made it more difficult to resolve the problems? What about working as a team made it easier to resolve the problems?

Lab 5 Reflection 4: So far, has having designated team member roles been useful to the overall progress of your program? In what ways? Give specific examples. Do you feel restricted by your designated role? Why or why not? Remember your team members won't see this, so feel free to be honest.

Lab 5 Reflection 5: Now that the program is done, what have you learned about researching, planning, and documenting the project? Say something about each of these phases. How does this learning process compare to the partnered lab work you completed during the first half of the semester? Which do you prefer and why?

Lab 5 Reflection 6: This week, you came together to integrate the parts of the project. What are the benefits of dividing the work on this project? Give examples from your group work. What are the drawbacks of dividing the work on this project? Give examples from your group work. What have you learned about implementing and documenting your design?

Lab 5 Reflection 7: This project is complicated. Now that you see your work as part of this larger piece, do you feel like your individual work contributed to the success of the 
overall project? How so? Describe your overall experience with this group project. What strengths and weaknesses did you observe about teamwork? What problems did you experience when you put the bot together? When you work in teams in the future, what would you apply from this experience? And what would you avoid doing?

\section{Data Analysis}

Linguistic analysis consisted of dividing student reflections into two separate groups to analyze: Labs 1-4 and Lab 5. Reflections were put into Wordsmith Tools 6.0, a concordancing program. In a concordance, lexical items are entered into the program and the contexts for the items are provided from the texts entered. (See Figure 2 for a screen shot of a concordance search for the verb decide.) In a concordance, the lexical item is placed in the center of the page with text surrounding it on either side. This vertical alignment allows the researcher to see the collocations, or words that co-occur with the lexical item in question.

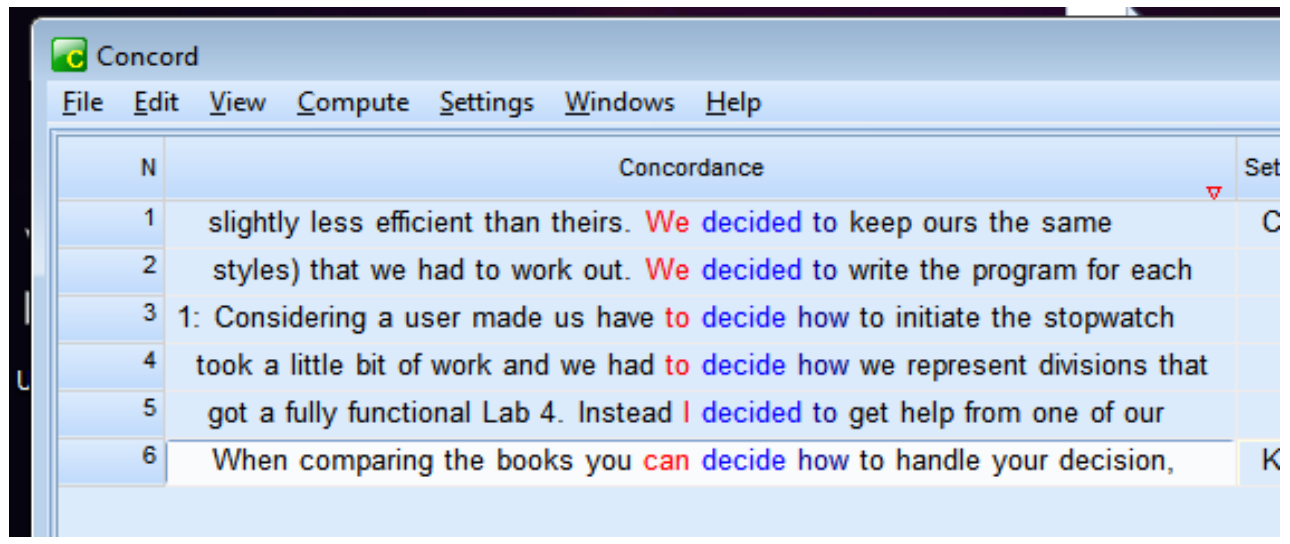

Figure 2: Concordancing. Figure shows an example of the verb decided.

Since student learning was of interest for this study, cognitive verbs were chosen for analysis. Searches were completed on the following verbs: learned, decide, know, and think. To discover whether there was a difference in the frequency of use of these cognitive verbs from the first part of the semester sequence (Labs 1-4), when the students worked in pairs, and the second (Lab 5), when the students were put into teams, paired T-tests were run.

\section{Data Presentation}

The following lexical items showed significant differences in number of times the lexical item was used between the first set of lab reflections (Labs 1-4) and the second (Lab 5): learned, think, decide, know.

Table 1 Paired T-tests Results

\begin{tabular}{ccccc}
\hline Labs 1-4 & Lab 5 & $T$ & df & $p$-value \\
$M(S D)$ & $M(S D)$ & & & \\
\hline
\end{tabular}




\begin{tabular}{llcrrr}
\hline Learned & $3.36(2.72)$ & $.28(.56)$ & 7.45 & 38 & $<.01$ \\
Think & $.62(.91)$ & $1.97(2.37)$ & -3.50 & 38 & $<.01$ \\
Decide & $.15(.43)$ & $.44(.72)$ & -2.06 & 38 & $<.05$ \\
Know & $.51(.85)$ & $1.15(1.48)$ & -2.28 & 38 & $<.05$ \\
\hline
\end{tabular}

The concordances for the four verbs were analyzed for pronoun use to determine the perspective from which the students were expressing their stance. Then these lexical items were examined for the presence of 3-5 word clusters and for their contexts. Wordsmith Tools compiled lexical items that frequently collocated. These contexts were then analyzed for what they could tell us about the stance of the students from the first to second part of the semester when the labs shifted from pair work to team work. Finally, the complement clauses were examined to determine the information the cognitive verbs were framing. Table 2 below shows that learned is the only verb that decreased in use from Labs 1-4 to Lab 5.

Table 2 Frequencies of Cognition Verbs

\begin{tabular}{llll}
\hline Verb & Labs 1-4 & Lab 5 & Total \\
\hline Learned & 131 & 51 & 182 \\
Decide* & 6 & 17 & 23 \\
Know & 20 & 45 & 65 \\
Think & 24 & 77 & 101 \\
\hline
\end{tabular}

*Decide has an asterisk because an asterisk allows Wordsmith Tools to search all forms of that lexical item (e.g. decided, decides, decide). The other three verbs were searched by the specific form because they were frequently occurring in the specific form searched.

The frequency of the use of learned in labs 1-4 can be partially explained by the fact that in Lab 4, students were asked to explain how they learned to integrate the interrupts. However, learned appeared in all reflections from labs 1-4, so other possible explanations also exist.

\section{Pronouns}

In looking at pronoun use (See Table 3), we can see that, except for decide, I occurred more frequently than the other pronouns in both sets of lab. This is not surprising since the students were asked to write their reflections individually. However, Lab 5 reflections focused mainly on group work. The use of I confirms the stance role of these cognitive verbs. That is, the writer is expressing a position toward the information following the verb. 
Table 3 Pronouns Used with Verbs

\begin{tabular}{|c|c|c|c|c|c|c|c|c|c|c|}
\hline & \multicolumn{5}{|c|}{ Labs 1-4 } & \multicolumn{5}{|c|}{ Lab 5} \\
\hline Verb & I & We & you & $3^{\mathrm{Id}}$ person & Other & I & $\mathrm{We}$ & You & $3^{\mathrm{rd}}$ person & Other \\
\hline Learned & 93 & 32 & 1 & 5 & 0 & 41 & 4 & 4 & 2 & 0 \\
\hline Decide* & 1 & 2 & 1 & 0 & 2 & 0 & 11 & 0 & 1 & 1 \\
\hline Know & 12 & 4 & 0 & 0 & 4 & 21 & 7 & 4 & 13 & 0 \\
\hline Think & 19 & 0 & 1 & 1 & 3 & 64 & 0 & 4 & 3 & 6 \\
\hline Total & 125 & 38 & 3 & 6 & 9 & 126 & 22 & 12 & 19 & 7 \\
\hline
\end{tabular}

\section{Learned}

Learned was the most frequently occurring cognitive verb in the group. There was an interesting cluster in Labs 1-4 as shown in Table 4 below.

Table 4 Learned (Labs 1-4)

\begin{tabular}{llll}
\hline $\mathrm{N}$ & Cluster & Freq. & Length \\
\hline 1 & LEARNED HOW TO & 50 & 3 \\
2 & I HAVE LEARNED & 26 & 3 \\
3 & HOW TO USE & 17 & 3 \\
4 & LEARNED HOW TO USE & 16 & 4 \\
5 & I VE LEARNED & 15 & 3 \\
6 & HAVE LEARNED HOW & 15 & 3 \\
7 & HAVE LEARNED HOW TO & 14 & 4 \\
8 & HOW TO USE THE & 13 & 4 \\
9 & I HAVE LEARNED HOW & 13 & 4 \\
10 & TO USE THE & 13 & 3 \\
\hline
\end{tabular}

An interesting question arose as to what it is the students learned how to do. The learned how to samples were analyzed for type of verb that occurred after the cluster and the results are shown in Table 5.

Table 5 Learned how to verb complements

\begin{tabular}{ll}
\hline \multicolumn{1}{c}{ Verb } & Number \\
\hline add & 1 \\
call an address & 1 \\
Communicate & 1 \\
Convert & 3 \\
Execute & 1 \\
Implement & 3 \\
integrate the interrupts & 5 \\
Jump & 1 \\
load (numbers and words) & 3 \\
Make & 2 \\
Manipulate & 3 \\
\hline
\end{tabular}




\begin{tabular}{ll}
\hline Math & 1 \\
memory map & 1 \\
Output & 1 \\
Print & 2 \\
read and write & 3 \\
send and receive data & 1 \\
Use & 16 \\
work (with switches) & 1 \\
\hline Total & 47 \\
\hline
\end{tabular}

The examination of the verbs that followed learned how to indicated that the students learned a variety of procedural skills in Labs 1-4. Use as the most frequently occurring verb in this cluster confirms the learning that the students reported as procedural rather than declarative.

In the clusters for Lab 5, learned how to does not appear. See Table 6 for Lab 5 clusters for learned.

Table 6 Learned clusters (Lab 5)

\begin{tabular}{lll}
\hline $\mathrm{N}$ & Cluster & Freq. \\
\hline 1 & I HAVE LEARNED & 7 \\
2 & LEARNED A LOT & 6 \\
3 & I LEARNED THAT & 6 \\
4 & LEARNED THAT IT & 5 \\
5 & I LEARNED A & 5 \\
\hline
\end{tabular}

The frequency of the use of the present perfect have learned rather than the simple past tense indicated that the students had an ongoing perspective toward their learning. That is, in examining the use of the cluster I learned a lot, it appeared that amount of learning was an aspect. In addition to the 6 from the cluster, there were 12 other instances of amount, most of which indicated much learning, a lot, more, so much, everything. There were three instances in which the students indicated little or no learning occurred "I have not learned much about...", "I have not really learned anything...", and "I learned very little in the labs". When students used that as a complementizer (14 occurrences), the material following that was expressed in more general ways than the material that followed how in Labs 1-4. For example, I learned that it is much easier to, or I learned that when working on a team. These indicated that the students acquired procedural knowledge that they were beginning to generalize and articulate.

It seemed, on the surface, that learned may not have functioned as a evaluation verb+complement, but in fact, the difference between the complementizer how to and the complementizer that showed that learn collocated a different position towards the kind of learning that followed in the complement clause. The shift between the two positions from the first set of reflections to the second set may indicate a growth in their ability to reflect on and implement what they learned: they showed, overall, an adaptive stance toward the kinds of learning that was completed in each half of the course. 


\section{Decide}

While there was a significant difference between the use of decide in reflections from Labs 1-4 and 5, decide was not a frequently occurring verb, and there were no clusters detected. However, the pronoun analysis showed that decision-making, in both Labs 1-4 and Lab 5 was not done individually - in both sets we was the pronoun used. Larger sets of data would need to be examined to determine any further role of decide. Interestingly, how occurred as a complementizer in three of the six occurrences of decide in Labs 1-4 but did not occur at all in Lab 5.

\section{Know}

Know presents another picture of how how to becomes a collocater with the cognitive verbs in Labs 1-4. Table 7 shows that the one cluster that appears in this set of reflections is know how to.

Table 7 Know (Labs 1-4)

\begin{tabular}{llll}
\hline $\mathrm{N}$ & Cluster & Freq. & Length \\
\hline 1 & know how to & 8 & 3 \\
\hline
\end{tabular}

In this cluster of appearances of know, the students expressed that they knew how to send, use, convert, and loop. However, stance was expressed in two negative expressions "we didn't know how to", "it was hard to know how to", "it was hard to know how to convert", but also implied future knowing in two instances, "I will need to know how to use", "I will have to get to know how to transform code",

When considering Lab 5 with the verb know, the clusters in Table 8 show that a pattern of negative+know emerges.

Table 8 Know (Lab 5)

\begin{tabular}{llll}
\hline N & Cluster & Freq. & Length \\
\hline 1 & DIDN T KNOW & 7 & 3 \\
2 & DO NOT KNOW & 6 & 3 \\
3 & KNOW WHAT TO & 5 & 3 \\
4 & T KNOW WHAT & 5 & 3 \\
5 & I DO NOT & 5 & 3 \\
6 & I DO NOT KNOW & 5 & 4 \\
\hline
\end{tabular}

Overall, of the 45 instances of know, 20 were couched in the negative. In addition, there were another nine complements that followed the verb that expressed a negative with an additional remark "we all know that hindsight is 20/20" which expresses a retrospective stance toward something that has not worked. The complementizers for know in Lab 5 grouped around what, as indicated by the cluster table, but also included examples of where, that, who. The five instances of what clustered with the negatives didn't, won't, don't and the use of the other complementizers also collated with the negative. I don't know is the most frequently occurring three-word bundle in conversational English ${ }^{17}$ and since reflective writing is an informal genre with a first person focus, this negative valence is not surprising. However, there is some 
indication in the data that the context of this 'not knowing' was balanced by a 'knowing' that followed. For example, one line included didn't know what to do followed by a new sentence beginning with However. Further investigation of this will need to be completed through additional studies.

\section{Think}

There were no clusters for think in Labs 1-4 reflections. Of the 19 first person instances of think, 10 were future oriented: "I think I will need to learn more plp", "I think I will need to master assembly", "I think this will be a good foundation..". This indicated an evaluation of possibility, which made sense for the first part of the semester when the students were looking to what they will learn. Table 9 shows the clusters for think for Lab 5.

Table 9 Think (Lab 5)

\begin{tabular}{llll}
\hline $\mathrm{N}$ & Cluster & Freq. & Length \\
\hline 1 & I THINK THE & 11 & 3 \\
2 & I THINK THAT & 9 & 3 \\
3 & I THINK I & 6 & 3 \\
\hline
\end{tabular}

The instances of I think the are complements without the complementizer. In this case, complements in addition to the I think the clauses without the that complementizer expressed possibility, obligation, and intention as well as named individuals, discussed problems and affective views: "it helped us start", "our team did really well", "we did a great job". The complements that followed that were more logical: "had we put more emphasis", "it actually ended up being", "I would choose to be more...". Again, as with learn and know, Lab 5 reflections showed a trend toward integration of the information and the procedural knowledge the students acquired.

After the clusters produced by Wordsmith Tools were analyzed, further analysis was completed on the types of $\mathrm{V}+\mathrm{Complement}$ clauses used with the four cognitive verbs. Hunston ${ }^{10}$ indicated that the multi-word units, clusters, with the V+complements have implications for evaluation. Table 10 shows the total number of examples analyzed for this study and the total number of Verb+complement clauses on the left side of the table. The right side of the table shows the specific types of complement clauses present by complementizer type. The following are examples of each type: that "I have learned that the UART reads..."; wh- (how) "We had to decide how we.."; infinitive (to "We decided to divide up the work..."; 0 (no complementizer) "I think I will need to know more plp,,,"

Table 10 Summary table of $\mathrm{V}+$ complement clause in all verbs

\begin{tabular}{|c|c|c|c|c|c|c|c|c|c|c|c|c|}
\hline Verb & \multicolumn{2}{|c|}{ Total items } & \multicolumn{2}{|c|}{$\mathrm{V}+\mathrm{CC}$} & \multicolumn{2}{|c|}{$\mathrm{V}+$ that } & \multicolumn{2}{|l|}{$\mathrm{V}+w h-$} & \multicolumn{2}{|c|}{ V+inf } & \multicolumn{2}{|c|}{ V+0 Comp } \\
\hline & $1-4$ & 5 & $1-4$ & 5 & $1-4$ & 5 & $1-4$ & 5 & $1-4$ & 5 & $1-4$ & 5 \\
\hline Learned & 131 & 51 & 68 & 19 & 12 & 16 & $58(50)$ & 18 & 0 & 0 & 0 & 0 \\
\hline Decide* & 6 & 17 & 6 & 11 & 0 & 1 & $3(3)$ & 1 & 3 & 8 & 0 & 1 \\
\hline Know & 20 & 45 & 13 & 28 & 2 & 2 & $11(8)$ & $16(5)$ & 0 & 0 & 0 & 10 \\
\hline Think & 24 & 77 & 16 & 59 & 3 & 9 & 0 & 0 & 0 & 0 & 13 & 50 \\
\hline
\end{tabular}

Note. $\mathbf{V}+\mathbf{C C}=$ verb + complement clause; $\mathbf{V}+\mathbf{i n f}=\mathrm{Verb}+$ infinitive clause (to), $\mathrm{V}+0=$ no 
complementizer.

As the left hand side of the table indicates, each of these four cognitive verbs collocated with a complement clause. Many times this collocation was proportionally high (see decide in Labs 1-4 or think in Lab 5). The right side of the table shows the type of complement clause that cooccurred with a particular verb. For example, know and think did not take infinitive clauses in this data set, but were preferred with decide. The numbers in parentheses indicate a subset of $w h$ clauses, the wh- infinitive clause includes how to and what to. The only instances of $w h$ infinitive clause that appeared in Lab 5 were the five instances with the verb know and this whinfinitive complementizer is what to as in didn't know what to do. The how to complementizer only appeared in Labs 1-4.

\section{Discussion}

The corpus-based analysis of the four cognitive verbs within the context of their subject pronouns, clusters and examination of the verb+complement construction for evaluation indicated that these verbs were used to position the students' perspectives on what they learned; thereby, helping to understand the type of knowledge the students were gaining.

The overwhelming use of the first person pronoun with these verbs showed the expected subjectivity expected for reflective work. The evaluation was explicit and engaged toward the information the students were presenting.

The presence of the wh-infinitive clause how to as a complementizer for three of the verbs for Labs 1-4 showed that procedural knowledge was being learned by students. This provided evidence that students were engaged in the research phase of the PLP at the beginning of the semester. Interestingly, this particular complement clause, when combined with learn, did not collocate to provide evaluation; however, when combined with know and decide. Often the evaluation in these cases indicates necessity.

The shift from the use of how to in Labs 1-4 to other complementizers in Lab 5 may show a shift in stance of the students toward what they learned. More interestingly, it may show how the reflective and evaluative abilities of the students improved in conjunction with the phases of the course. It was evident in examining the verb+complement multi-word groups that the evaluation toward the propositions of student learning reflected a more integrated understanding.

\section{Summary}

The PLP learning experience in the microprocessors course was designed to actively engage students in the learning process. The results of this study confirmed that this was a learning experience in which students initially reported much procedural knowledge being acquired as indicated by the prevalent use of the $\mathrm{V}+$ wh- infinitive complements how to across three cognitive verbs. Hunston's and others' claim ${ }^{19}$ that that-, to-infinitive, and wh-clauses "package information in such a way that makes that information available for subjective comment". The students were able to articulate their acquisition of procedural knowledge and comment on the value of that knowledge acquisition through the use of the cognitive $\mathrm{V}+$ Complement stance marker. This is confirmation of Hunston's ${ }^{14}$ hypothesis that $w h$-infinitive complements combine 
in multi-word combinations to express evaluation. The fact that students seemed to acquire both procedural and informational component throughout the semester seemed to confirm Willingham and Goedert-Exchmann's ${ }^{25}$ argument that learners tend to acquire both simultaneously in the process of learning a new procedure. This initial study indicated that the use of a corpus-based discourse analytic approach can give insight into the types and evaluation of learning created by the use of PLP.

\section{References}

1. Mulia W, Fritz D, Sohoni S, Kearney K, Mwavita M. PLP: A Community Driven Open Source Platform for Computer Engineering Education. International Journal of Engineering Education 2013;29(1):215.

2. Fritz D, Mulia W, Sohoni S. The Progressive Learning Platform Website.

3. David Fritz, Wira Mulia, Sohum Sohoni. The Progressive Learning Platform. Paper presented at Workshop on Computer Architecture Education; San Antonio, TX.

4. Schon DA. Reflective Practitioner: How Professionals Think In Action. Basic Books; 1984.

5. Stevens DD, Cooper JE. Journal Keeping: How to Use Reflective Writing for Learning, Teaching, Professional Insight and Positive Change. Stylus Publishing; 2009.

6. Bolton G. Reflective practice: Writing and professional development. SAGE Publications Limited; 2010.

7. Stephen Ekwaro-Osire, Peter O. Orono. Design notebooks as indicators of student participation in team activities. Paper presented at Frontiers In Education Conference-Global Engineering: Knowledge Without Borders, Opportunities Without Passports, 2007. FIE'07. 37th Annual;

8. Gina Navoa Svarovsky, David Williamson Shaffer. Design meetings and design notebooks as tools for reflection in the engineering design course. Paper presented at Frontiers in Education Conference, 36th Annual;

9. Hawkins S, Coney MB, Bystrom K. Incidental writing in the engineering classroom. J Eng Educ 1996;85(1):27-33.

10. Hunston S. Corpus approaches to evaluation: Phraseology and evaluative language. Taylor \& Francis; 2011.

11. Hunston S. Lexis, word form and complementation pattern: A corpus study. Functions of language 2003;10(1):31-60.

12. Partington A. Patterns and meanings: Using corpora for English language research and teaching. John Benjamins Publishing Company; 1998. 
13. Biber D. University Language: A corpus-based study of spoken and written registers. Philadelphia: John Benjamins; 1996.

14. Hunston S, Thompson G. Evaluation in text: Authorial stance and the construction of discourse. Oxford University Press on Demand; 2001.

15. Hunston S, Sinclair J. A local grammar of evaluation. Evaluation in Text: Authorial stance and the construction of discourse 2000;:74-101.

16. Conrad S, Biber D. Adverbial marking of stance in speech and writing. Evaluation in text: Authorial stance and the construction of discourse 2000;:56-73.

17. Biber D, Johansson S, Leech G, Conrad S, Finegan E, Quirk R. Longman grammar of spoken and written English. MIT Press; 1999.

18. Hyland K. Metadiscourse. New York: Continuum; 2005.

19. Hyland K, Tse P. Hooking the reader: a corpus study of evaluative $<\mathrm{i}>$ that $</ \mathrm{i}>$ in abstracts. English for specific purposes 2005;24(2):123-39.

20. Du Bois JW. The stance triangle. Stancetaking in discourse: Subjectivity, evaluation, interaction $2007 ;: 139-82$.

21. Schunk D. Learning Theories: An Educational Perspective. 6th ed. Upper Saddle River, NJ: Prentice Hall; 2011.

22. Schraw G. Knowledge: Structures and processes. Handbook of educational psychology 2006;2:245-60.

23. Anderson JR. Learning and memory. John Wiley New York; 2000.

24. Anderson JR. Skill acquisition: Compilation of weak-method problem solutions. Psychol Rev 1987;94(2):192-210.

25. Willingham DB, Goedert-Eschmann K. The relation between implicit and explicit learning: Evidence for parallel development. Psychological Science 1999;10(6):531-4.

26. S. Sohoni, D. Fritz, W. Mulia. Transforming a Microprocessors Course through the Progressive Learning Platform. Paper presented at ASEE Midwest Conference; Russelville, AR. 